\title{
Applying Memory Research on Campus
}

Jennifer M. Talarico

\author{
Department of Psychology, Lafayette College, Easton, PA, USA
}

Most of us researchers are employed at institutions of higher education where we recruit our undergraduate students to serve as participants in our research. We are frequently criticized for using this convenience sample of "people from Western, educated industrialized, rich and democratic (WEIRD) societies" (Henrich, Heine, \& Norenzayan, 2010, p. 61). Political adversaries attack our scholarship as not being a sound investment of federal funding (Kelly, 2011). I will argue that we can directly refute both of these criticisms by attending more thoughtfully to the nature of our students and of our institutions and utilizing these attributes to the benefit of all involved. ${ }^{1}$

The application of memory research to education is the most obvious way in which undergraduate samples can be particularly instructive. How do students acquire, rehearse, and retrieve semantic information? How does stimulus presentation (e.g., text, lecture, or demonstration) influence later retention of that material? What role does episodic memory for in- and out-of-class experiences play in the retention of semantic material? Investigations like these are contributing to both educational practice and basic understanding of mnemonic processing (Dunlosky, Rawson, Marsh, Nathan, \& Willingham, 2013). Sharing the results of these investigations with Centers for Teaching \& Learning is one way we might effect positive changes in our immediate communities. However, the fact that our students are students is but only one aspect that might be useful for investigation.

Developmentally, typical US undergraduates represent an available sample of individuals in the "emerging adulthood" stage. What are the implications of this developmental period for memory processing? How does what we know about brain development at this age contribute to our understanding of cognitive functioning? Taking advantage of the availability of this sample for a period of 4 years should allow for interesting longitudinal work on the changes that occur within this highly plastic time frame. Furthermore, these findings can inform curriculum decisions ranging from what courses ought to be required and how they ought to be sequenced to how long class periods ought to last and at what times of day they ought to be offered to maximize student acquisition and retention of material. Similar applications of psychological research on sleep patterns in late adolescence that lead to later start times for high schools have improved academic performance (Edwards, 2012).

External characteristics of undergraduate samples are also relevant, particularly within autobiographical memory research. Many undergraduate students have undergone a substantive transitional life event (i.e., moving away from home). The affective, social, and cognitive aspects of transitional life events influence how they will be remembered. These events show an increased likelihood of recall as well as enhanced vividness of the memory. The mechanism of enhancement has been productively explored with systematic examination of memory for these events (Pillemer, Goldsmith, Panter, \& White, 1988; Talarico, 2009). Understanding how and why these events are memorable can also be useful when designing campus orientation programs or arranging how and when students and their families part ways.

Other experiences may not be as universal, but may still provide opportunities to study how particular experiences are remembered. For example, longitudinal designs could be implemented to study domestic students before, during, and after study abroad experiences. The duration and nature of these programs as well as the destination characteristics could all be investigated for differential influence on a host of attitudes, beliefs, and behaviors. The cooperation of administrators within study abroad programs will be necessary to conduct such research efficiently and effectively. The results of this research should also be useful to them for program assessment.

There are many other opportunities to partner with administrative offices to conduct mutually-beneficial research. Kuwabara and Pillemer's (2010) study of how selective retrieval of positive memories of one's undergraduate experience can increase participants' willingness to donate to the institution demonstrates how basic questions about the function of autobiographical memory can have immediate practical consequences. Student Life directors might seek to improve student satisfaction with on-campus

1 The examples here are drawn exclusively from US undergraduate institutions due to space constraints and because that is what I know best. My hope is to inspire consideration of the specific characteristics present at other institutions. 
amenities while researchers investigate the determinants of affective evaluation and mnemonic change. The Alumni Affairs Office can help researchers recruit participants from across the life span to better understand the developmental trajectory of memory processing all while strengthening the connection between the institution and its alumni.

There are other, stable characteristics of student groups that may be useful for memory investigators. The easy division of undergraduates into subgroups with high self-identification (e.g., fraternity/sorority members, class year peer groups, etc.) can facilitate investigation of social-cognitive factors in memory. One area where a clear in-group/outgroup dynamic can be seen is within college athletics, particularly with long-standing rivalries. For example, Botzung, Rubin, Miles, Cabeza, and LaBar (2010) claim that "the Duke - UNC basketball rivalry ... is a heralded sports tradition that is central to the personal identity of hardcore fans and a cornerstone of socialization in the local environment" (p. 2133). Such strong social identification has shown to systematically influence memory for events via modulation of emotional reactions (Botzung et al., 2010), rehearsal of event details (Talarico \& Moore, 2012), and causal attributions (Hastorf \& Cantril, 1954). It is easy to imagine how this research could be employed by campus Athletics departments to increase team support. Similarly, how media coverage frames sporting events and their outcomes will have consequences for mnemonic recall; this can be of interest to both public relations officers and to memory investigators.

Of course, our campuses are not immune from larger societal issues. The enrollment of veterans of the wars in Afghanistan and Iraq provides an opportunity to examine how memory for life events changes as a function of a dramatic shift in context. How are memories of wartime experiences differentially recalled? What stimuli serve to trigger intrusive memories and what are the affective, behavioral, and cognitive consequences of those memories? More broadly, what factors predict successful completion of a degree program? The answers to these questions will benefit veterans and psychologists alike.

By thinking more deliberately of everyday memory demands and about the characteristics of the samples that are readily available to us, we can conduct useful and important work that both enhances our understanding of memory processing and improves the institutions that we serve.

\section{References}

Botzung, A., Rubin, D. C., Miles, A., Cabeza, R., \& LaBar, K. S. (2010). Mental hoop diaries: Emotional memories of a college basketball game in rival fans. The Journal of Neuroscience, 30, 2130-2137.

Dunlosky, J., Rawson, K. A., Marsh, E. J., Nathan, M. J., \& Willingham, D. T. (2013). Improving students' learning with effective learning techniques: Promising directions from cognitive and educational psychology. Psychological Science in the Public Interest, 14, 4-58.

Edwards, F. (2012). Early to rise? The effect of daily start times on academic performance. Economics of Education Review, 31, 970-983.

Hastorf, A. H., \& Cantril, H. (1954). They saw a game: A case study. Journal of Abnormal \& Social Psychology, 49, 129134.

Henrich, J., Heine, S. J., \& Norenzayan, A. (2010). The weirdest people in the world? Behavioral and Brain Sciences, 33, 6183. doi: 10.1017/S0140525X0999152X

Kelly, H. O. (2011, June). New congressional attacks on behavioral science (American Psychological Association Government Relations update). Retrieved from http:// www.apa.org/science/about/psa/2011/06/congressionalattacks.aspx

Kuwabara, K. J., \& Pillemer, D. B. (2010). Memories of past episodes shape current intentions and decisions. Memory, 18, 365-374

Pillemer, D. B., Goldsmith, L. R., Panter, A. T., \& White, S. H. (1988). Very long-term memories of the first year in college. Journal of Experimental Psychology: Learning, Memory, \& Cognition, 14, 709-715.

Talarico, J. M. (2009). Freshman flashbulbs: Memories of unique and first-time events in starting college. Memory, 17, 256-265.

Talarico, J. M., \& Moore, K. M. (2012). Memories of "The Rivalry": Differences in how fans of the winning and losing teams remember the same game. Applied Cognitive Psychology, 26, 746-756.

Jennifer M. Talarico

Department of Psychology

307 Oechsle Hall

Easton, PA 18042

USA

Tel. $+1610330-5248$

Fax $+1610330-5349$

E-mail talaricj@lafayette.edu

The Opinion section of this journal aims to encourage further inquiry and debate. The opinions expressed in the contributions to this section are those of the authors and not necessarily those of the journal, the editors, or the publisher. 